\title{
Tratamiento Quirúrgico por Vía Abdominal de la Inversión Crónica de la Matriz
}

\author{
Trabajo presentado por el DR. RICARDo BEChARA Z., de Mon- \\ tería, Departamento de Córdoba, a la Primera Convención Nacionai \\ de Obstetricia y Ginecología.
}

Este trabajo es el fruto de nuestra experiencia personal durante varios años en el campo de la Obstetricia y la Ginecología y tiene como fin primordial hacer resaltar las bondades de la intervención por vía abdominal de la inversión crónica de la matriz.

Las estadísticas son confusas y no guardan relación unas con otras; sólo hemos visto dos inversiones crónicas de la matriz durante los años de internado en el Hospital de San Vicente de Paúl de Medellin y tuvimos la feliz oportunidad de avudar a los va fenecidos maestros Juan B. Montoya y Flórez y Gil J. Gil en las correspondientes intervenciones, pero desgraciadamente ambos casos terminaron en muerte: el uno fue operado por el método de Spinelli y el otro por la Pecnica de Kustner y desde entonces no quedamos satisfechos con tales practicas porque parecía que, de salvarse las pacientes, era demasiada injuria la que se le propinaba a los tejidos uterinos que quedaban al final en condiciones interiores. Estos datos anteriores se refieren al servicio de Ginecologia, pues en los 3.308 casos de gestación atendidos en el servicio de Maternidad y presentados por nosotros en tesis de grado no pudimos anotar ni un sólo caso de inversion y en los cerca de dos mil partos atendidos durante los años de ejercicio profesional tampoco hemos tenido esta clase de episodio.

Desde hace 13 años, ejerciendo en Montería hemos tenido oportunidad de operar siete (7) casos de inversión crónica de la matriz con los resultados que más adelante anotaremos, pero debemos advertir que dichos casos sucedieron fuera de la ciudad y con ello queremos hacer sobresalir el hecho de que los partos - raíz de los cuales se hizo la inversión uterina no fueron atendidos por médicos sino por las célebres "parteras" que en nuestro medio cuentan con más víctimas que el cáncer. 
Como etiopatogenia citan la primiparidad, el parto rápido, el hidramnios, la inserción fúndica de la placenta, la astenia, la inercia uterina, el desgarro bilateral del cuello y la cortedad del cordón. Los datos suministrados por las pacientes objeto de este trabajo coinciden en afirmar que las fuertes tracciones sobre el cordón motivaron la inversión de la matriz y este dato lo considero interesante porque según mi criterio de todas las teorias la más acertada pudiera ser la de las maniobras bruscas para ejecutar el alumbramiento artificial en concomitancia con inercia de la matriz y con inserción fúndica de la placenta.

La edad de las pacientes oscila entre 22 y 38 años. Ninguna era primigesta. En una de ellas la inversicn databa de dos meses; en dos, de tres meses; en una, de cuatro meses y medio; en una de seis meses y en las dos restantes, de cinco.

En la paciente cuya inversión era de seis meses tuve necesidad de hacer histerectomía subtotal porque los tejidos uterinos estaban prácticamente sin nutrición y eran muy frágiles.

Cuatro de las siete pacientes han tenido gestaciones y partos normales posteriores a la intervecnión.

No entro en detalles de definir lo que es una inversión crónica de la matriz ni me detengo en el diagnestico diferencial, el cual resulta a la postre muy sencillo con sólo pensar en dicha entidad en presencia de un tumor duro y redondeado que ocupa la vagina añadido a la ausencia del cuerpo uterino en su lugar anatómico.

El pronóstico de la inversión crónica de la matriz es hoy satisfactorio. En mi corta estadística, por ejemplo. no he tenido ni una sola defunción y a medida que la cirugía progresa y los medios hospitalarios mejoren llegará el día en que se pueda afirmar que toda paciente que haya resistido la prueba de la inversión aguda con todo su cortejo de peligros, debe salvarse.

Ninguna de las pacientes operadas por mí tuvo repetición de la inversión en los partos posteriores a la intervención.

De todas las técnicas empleadas por vía vaginal solamente la de Spinelli tiene partidarios porque tiene la ventaja sobre el método de Kustner que el campo operatorio es más amplio, los tiempos más sencillos y se puede, en caso necesario, corregir cualquier defecto de posición de la matriz, especialmente la retrodesviación.

Ha habido otras técnicas que paso a enumerar muy a la ligera: La historia data desde Hipócrates quien aconsejaba especialmente la reducción manual sin que se obtuviesen éxitos halagadores y siguiendo el orden cronológico, magistralmente expuesto por Crossen, aparece Temisión que en el año 50 antes de Cristo se mostro partidario de la amputacion del cuerpo uterino; más tarde aparecieron Aram (1883), Barnes (1891), Thomas (1896), Browne (1898) con dis 
tintas técnicas que oscilaban entre la división de las fibras del anillo cervical v la dilatación del mismo por distintas vías y por último, recientemente, estuvo de moda la histerectomía total por vía vaginal. Ya en 1893 Kustner puso en boga su técnica consistente en una larga incisión posterior de la pared uterina que llegaba hasta cerca del orificio externo del cuello y abriendo el Douglas hacía la reducción manual. Este método fue modificado por Piccolj y Morisan quienes dividian en su totalidad la pared posterior de la matriz lo cual facilitaba la reinversion (1896). Menos de un lustro después Spinelli estableció la técnica que lleva su nombre consistente en la división del fórnix anterior vaginal con abertura del fondo de saco vesico uterino y sección completa, total, de la pared anterior de la matriz hasta el fondo, lo cual contribuve a la suavidad de las maniobras para voltear el útero.

Por via abdominal se pueden ejecutar tres operaciones que apenas difieren on detalles: la de Huntigton que consiste, previa abertura del abdomen por la línea media infraumbilical, en hacer presa con pinzar de garras finas de la porcion invaginada a cada lado y por dentro de dicha porción e ir haciendo tracción suave, pero cambiando el sitio de las pinzas a medida que se va haciendo la reinversion. Debemos confesar que con este método hemos fracasado por no haberlo empleado cuando realmente está indicado, es decir, dentro de los tres dias de establecida la inversión para no darle tiempo al cuello de constreñirse demasiado.

Las otras dos técnicas son la de Dobbin con incisión del rodete anterior cercano a la vejiga y la de Haultan con incisión en el centro del semicírculo posterior. Hacemos constar que solamente hemos practicado esta última técnica, es decir, la de Haultain en todos los casos y que siempre hemos obtenido éxito rotundo.

A continuación pasamos a describir la técnica de Haultain:

Incisicn mediana infraumbilical exposición del campo operatorio, incision en el centro del rodete posterior en una extensión de 4 ctms. y en sentido anteroposterior, aplicación de dos pinzas de Allis a los lados y por dentro de la incision para traccionar suavemente sobre la pared uterina invertida. Algunos cirujanos introducen un dedo a través del ojal que se hace en el rodete posterior para hacer presion sobre el fondo uterino facilitando así la reposición del organo, pero preferimos que un ayudante ejecute esta misma maniobra por via raginal ,es desir, a medida que se tracciona con las pinzas de Allis el ayuciante introduce uno o dos dedos por la vagina y hace presión suave y sostenida en el fondo uterino lo cual favorece grandemente la reducción. Terminadas estas maniobras se cierra la brecha uterina con puntos separados y por último se cierra el abdomen.

Cuando los ligamentos redondos se notan alargados y flácidos acostumbramos acortarlos y generalmente empleamos la técnica de Simpson modificada por 
Crossen y a la cual nos hemos permitido el lujo de añadirle otra ligera modificación que consideramos definitiva para el resultado ulterior: Simpson fija los ligamentos con tres puntos en la cara interna de la aponeurosis del recto-interior; Crossen hace eso mismo y mediante dos puntos de transfición uno en cada ligamento, acerca éstos a la línea media, pero nosotros no ejecutamos esta maniobra así sino que además de los puntos de Simpson con un solo hilo atravesamos la aponeurosis de un lado de fuera hacia dentro, atravesamos el ligamento de ese mismo lado, luégo el ligamento del lado opuesto y por último la aponeurosis del lado opuesto y de dentro hacia fuera para anudar en plena línea media.

La operación de Haultain es la ideal para tratar por vía abdominal la inversión crónica de la matriz; es fácil de ejecutar, se hace en corto tiempo y sin gran pérdida de sangre y tiene la ventaja de que no lesiona la matriz en el cuerpo lo cual es de suma importancia para las gestaciones posteriores. Hay que tener en cuenta que esta operación debe hacerse cuando la involución uterina hava terminado y en ausencia de infección. 